\begin{tabular}{|l|l|l|l|l|l|l|}
\hline InterteXto & Uberaba & UFTM & v. 1 & p. 35-55 & 2008 - jan. / jun. & ISSN 1981-0601 \\
\hline
\end{tabular}

\title{
O RECONHECIMENTO DA ANÁFORA CONCEITUAL
}

\section{THE RECOGNITION OF THE CONCEPTUAL ANAPHOR}

\begin{abstract}
Adriana da Silva ${ }^{1}$
\section{Resumo}

Neste trabalho apresentamos uma pesquisa sobre a leitura e compreensão das anáforas conceituais. A anáfora conceitual não concorda em número com seu antecedente textual, assim, ambos não são correferenciais. Usamos a Teoria dos Frames para explicar como os leitores relacionam, conceitualmente, anáfora e antecedente num texto, a partir de seus conhecimentos contextuais e de mundo. Realizamos um experimento de leitura em alunos universitários no qual verificamos se os sujeitos seriam capazes de identificar o referente da anáfora conceitual e se a reconheceriam como gramaticalmente correta e coerente. Verificamos que os alunos compreendem a anáfora conceitual, mas não a consideram natural. Dessa forma, podemos afirmar que a leitura é um processo dinâmico e que a influência do leitor nesse processo é extremamente relevante, pois pode utilizar estratégias diferenciadas para construir o sentido do texto.
\end{abstract}

Palavras-chave: anáfora conceitual; compreensão; frames; leitura; estratégias.

\begin{abstract}
In this work we present a research about reading and comprehension of conceptual anaphors. These are anaphors that do not agree in number with their antecedents. So anaphors and antecedents have not the same reference. We use the Frames Theory to explain how people understand the relation between anaphors and antecedents in a text using their world knowledge and the context. In one experiment with subjects from a University, we investigate how people understand the conceptual anaphors. Subjects rated sentences containing conceptual anaphors to be linguistically correct and indicated the referente of these anaphors. We found that subjects understand conceptual anaphors but they don't consider them natural. Our conclusion is tat reading is a dynamic process and that readers have a important role in this process.
\end{abstract}

Key-words: Conceptual anaphors; comprehension; frames; reading; skills.

\section{Introdução}

${ }^{1}$ adriasilva@terra.com.br 
Para compreendermos um texto, baseamo-nos não só em aspectos lingüísticos, como a coesão entre os sintagmas, a concordância morfológica entre itens lexicais, por exemplo, que serve como pista textual, mas também em aspectos extralingüísticos, como nossos conhecimentos de mundo, que nos permitem criar representações mentais daquilo que lemos ${ }^{2}$. Baseando-nos nisso, consideram-se as anáforas como pistas textuais que ajudam o leitor a estabelecer a compreensão do texto. Elas aparecem num texto como elementos que permitem ao leitor estabelecer relações entre aspectos lingüísticos e extralingüísticos. Por isso, estudá-la é importante e pode ajudar-nos a entender mais como se dá a compreensão textual.

Neste artigo, verificamos se alunos universitários reconhecem as anáforas conceituais e se as aceitam naturalmente. Usamos a Teoria dos Frames para explicar como os leitores relacionam, conceitualmente, anáfora e antecedente num texto, a partir de seus conhecimentos contextuais e de mundo. Realizamos um experimento de leitura em alunos universitários para verificar se eles seriam capazes de identificar o referente da $A C$ e se a reconheceriam como gramaticalmente correta e coerente.

Primeiramente, apresentamos a anáfora conceitual e a teoria para explicála, depois, o experimento realizado na pesquisa, assim como os resultados obtidos e a discussão.

\section{Anáfora conceitual}

${ }^{2}$ Garnham e Oakhill (1992) consideram que as estruturas que encontramos nos textos podem ser encontradas nos eventos diários de nossas vidas e essas estruturas do mundo nos ajudam a compreender os textos através das representações mentais. Ou seja, nosso conhecimento de mundo é codificado em nossas mentes e influencia nossas leituras. 
Há casos em que as anáforas não reativam referentes previamente apresentados no texto e não respeitam critérios lingüísticos como, por exemplo, o da restrição morfológica (TYLER e MARSLEN-WILSON, 1982), segundo a qual, a anáfora e seu antecedente devem apresentar os mesmos traços de gênero e número. Neste trabalho, analisamos a anáfora conceitual (AC), aquela que é representada por um Pro [+PI] que remete a um antecedente textual, um SN ou $\mathrm{N}$ $[-P I]$.

(1). Comprei um FIAT. Eles são muito potentes.

Em (1) AC Eles tem como antecedente um FIAT, porém a anáfora não o retoma diretamente. $A$ interpretação exige que se ativem possíveis sentidos para o referente, de tal forma que se deve lê-lo como carros. Assim, o pronome eles não se refere mais a um FIAT, mas aos carros produzidos pela FIAT. O leitor deverá colaborar com o escritor do texto e considerar a não-concordância entre o antecedente e a anáfora como uma pista para encontrar o referente anafórico e estabelecer a coerência textual. Para explicar como o leitor organiza seus conhecimentos; para entender a relação conceitual entre a $A C$ e o item lexical antecedente, usamos a Teoria dos Frames (BARSALOU, 1992). Através dela, explicaremos que, ao ler cada item lingüístico, o leitor ativa conceitos que se associam durante a leitura.

A violação da regra morfológica pode representar uma dificuldade a mais no complexo processo de leitura e compreensão. Assim, ao detectar o pronome anafórico, o leitor pode ter dificuldade em compreender o uso do pronome, pois ele não está retomando um antecedente, mas remetendo a um antecedente a partir do qual o leitor compreende conceitualmente a anáfora. Conseqüentemente, maiores cálculos inferenciais seriam necessários para a compreensão da anáfora conceitual. A anáfora conceitual é representada no texto por um pronome (Pro) 
plural associado conceitualmente a um antecedente (sintagma nominal) singular. Assim, para compreendê-la, o leitor deve associar conceitualmente este a aquele.

$\mathrm{Na}$ verdade, todo leitor realiza inferências para interpretar qualquer tipo de anáfora, mas, aparentemente, a conceitual necessita de maiores cálculos inferenciais já que não retoma o seu antecedente e também não obedece à restrição morfológica. Optamos pela Teoria dos Frames para explicar como os leitores compreendem as anáforas conceituais, pois essa teoria permite o tratamento dinâmico da leitura com base em aspectos lingüísticos e extralingüísticos. Partimos da hipótese de que para compreendê-las, os leitores realizam representações de itens textuais, associando-as a seus conhecimentos.

Acreditamos que, durante a leitura, para compreender os itens lexicais de um texto, o leitor ativa frames que não ocorrem independentemente, mas associados. Um frame pode ser considerado uma maneira de formalizarmos as nossas representações mentais e organizarmos nossos conhecimentos. Ele é formado por conceitos $^{3}$ e relações entre esses conceitos que são codificados em itens lexicais e construções gramaticais. Consideramos que o escritor usa a AC como uma ferramenta para criar um significado e guiar o leitor pelo texto; já o leitor deve usá-la como um recurso para compreender o texto. As palavras e construções gramaticais de um texto evocam uma compreensão, ou um frame, planejado pelo escritor, a partir de associações de conceitos, e o leitor evoca um frame a partir desse texto a fim de compreendê-lo.

A Teoria dos Frames proporciona uma representação do conhecimento humano que é desenvolvido a partir de nossas experiências de vida. Como salienta Barsalou (1992, p. 27), as pessoas não armazenam componentes representacionais sem relacionar uns aos outros e têm um extensivo

\footnotetext{
${ }^{3}$ Conceito é representação a partir de uma palavra que combina conhecimento semântico e de mundo.
} 
conhecimento sobre as relações entre eles. A Teoria dos Frames proporciona uma representação do conhecimento humano que abrange uma grande variedade de representações conceituais. Segundo BARSALOU (1992), os frames não podem ser considerados como rígidas configurações de atributos independentes, mas como estruturas relacionais dinâmicas cuja forma é flexível e dependente contextualmente. Assim, consideramos os frames como uma estrutura representacional de conceitos relacionados que podem representar todos os tipos de categorias (animadas, objetos, localizações, eventos físicos, mentais e assim por diante). Além disso, podem representar exemplares, eventos, seqüências de eventos, protótipos, membros de um grupo, taxonomias e subordinações.

A compreensão da AC depende, portanto, do leitor, que tem como tarefa ativar seus conhecimentos lingüísticos e extralingüísticos, selecionar alguns conceitos necessários para a compreensão do texto e integrá-los, de modo a estabelecer a coerência textual.

\section{0 experimento}

Do ponto de vista metodológico, para o estudo da anáfora conceitual, realizamos um experimento, no qual procuramos verificar se após a leitura de textos curtos com anáforas conceituais, os universitários seriam capazes de identificar os referentes das anáforas e se reconheceriam essas anáforas como gramaticalmente corretas e coerentes. Pretendíamos verificar como os sujeitos reconheceriam as $\mathrm{AC}$, se eles as perceberiam como naturais ou não, pois verificamos que esse tipo de anáfora é muito utilizado na fala, mas não sabemos como as pessoas a recebem.

\subsection{Metodologia}


Aplicamos o experimento em 21 universitários, alunos do primeiro período dos cursos de Química e de Física. Esses alunos foram escolhidos porque acreditávamos que por serem dos cursos de exatas, não estariam tão preocupados com questões lingüísticas e, dessa forma, não fariam pré-julgamento quanto ao uso da AC.

Utilizamos um exercício composto por três textos curtos: um elaborado, um retirado de Marcuschi (2000) e outro falado por uma professora durante uma reunião escolar. Cada texto apresentava uma AC e quatro perguntas para verificarmos se o sujeito perceberia a relação entre o pronome e seu antecedente como possível, natural e sem causar prejuízo para a coerência do texto e se seria capaz de indicar o referente anafórico.

Os textos e perguntas utilizados neste experimento são apresentados na Quadro 1:

1. Depois do colégio, minha irmã foi trabalhar na IBM. Eles fizeram uma boa proposta para ela.

a. Este texto apresenta algum tipo de erro? Justifique sua resposta.

b. Este texto é coerente? Justifique sua resposta.

C. A que palavra o pronome Eles se refere?

d. O pronome Eles poderia estar relacionado a uma outra palavra? Se sim, qual seria esta palavra?

2. Aqui no Rio tinha uma espécie de banana parecida...parece que se não me engano era banana-figo que eles chamam aqui no Rio...mas ainda lá é muito maior que a banana-figo /.../

a. Este texto apresenta algum tipo de erro? Justifique sua resposta. 
b. Este texto é coerente? Justifique sua resposta.

c. A que palavra o pronome Eles se refere?

d. O pronome Eles poderia estar relacionado a uma outra palavra? Se sim, qual seria esta palavra?

3. Nem tudo pode levar para casa. A turma da manhã fez um sorvete aqui e a da tarde um bolo. O sorvete não dava para mandar para casa. Já o bolo a gente enrolou e eles levaram para casa.

a. Este texto apresenta algum tipo de erro? Justifique sua resposta.

b. Este texto é coerente? Justifique sua resposta.

C. A que palavra o pronome Eles se refere?

d. O pronome Eles poderia estar relacionado a uma outra palavra? Se sim, qual seria esta palavra?

TABELA 1:Material usado no primeiro experimento

\subsection{Análise}

A partir das respostas dos alunos, realizamos uma análise quantitativa simples em cada etapa desse experimento. Verificamos as respostas para cada pergunta, contabilizando-as como positivas, negativas e em branco. As justificativas dos alunos quando apresentadas também foram contabilizadas. A mesma metodologia foi utilizada para a pergunta sobre a coerência do texto. Sobre a identificação do referente, contabilizamos as respostas em branco, as não esperadas (não relacionadas à $\mathrm{AC}$ ) e as esperadas (tanto as [- PI], concordando com o antecedente, como as [+PI], concordando com a AC). E, por último, transformamos as respostas contabilizadas em percentual. 


\section{Resultados}

Ao questionar os alunos sobre a possibilidade, ou não, de erros nos textos, pretendíamos verificar se eles aceitariam a $A C$ ou se a considerariam como um erro gramatical. Os dados revelaram que sujeitos oscilaram quanto à indicação de erros nos textos, mas a maioria considerou que estes apresentavam erros (TAB. 1).

\begin{tabular}{lccc}
\hline Respostas & Sim & Não & Branco \\
\hline Porcentagem & 54 & 43 & 3
\end{tabular}

TABELA 2: Percentual de resposta sobre a presença de erros nos textos

Apenas $14 \%$ dos sujeitos indicaram a falta de concordância como um erro textual, considerando a anáfora como agramatical e, portanto não natural para eles. Isso indica que a maioria aceitou a AC.

Ainda observando as respostas dos alunos para a primeira pergunta, verificamos que elas variaram em função do texto (Gráfico 1).

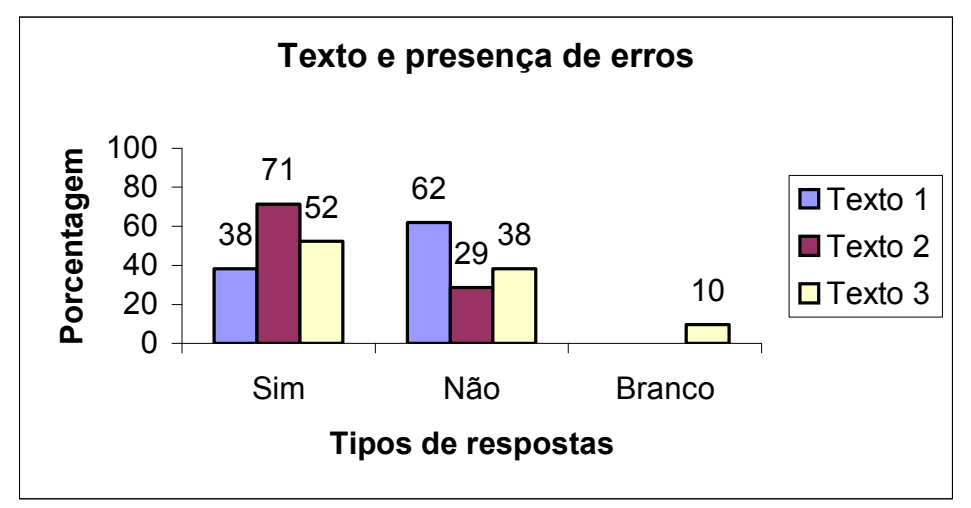

Gráfico 1: Influência dos textos na indicação de erros. 
Assim, de acordo com as respostas dos alunos, o texto 2 foi considerado como o mais errado, e o menos, o 1. Quando perguntamos aos alunos se os textos contendo $\mathrm{AC}$ eram coerentes, verificamos que a maioria $(56 \%)$ respondeu afirmativamente (TAB. 3).

\begin{tabular}{lccc}
\hline Respostas & Sim & Não & Branco \\
\hline Porcentagem & 56 & 41 & 3
\end{tabular}

TABELA 3: Percentual de resposta sobre a coerência dos textos.

Isso indica que a maioria não detectou incoerência nos textos, porém, constatamos, novamente, que o texto influenciou na resposta dos alunos (Gráfico 2).

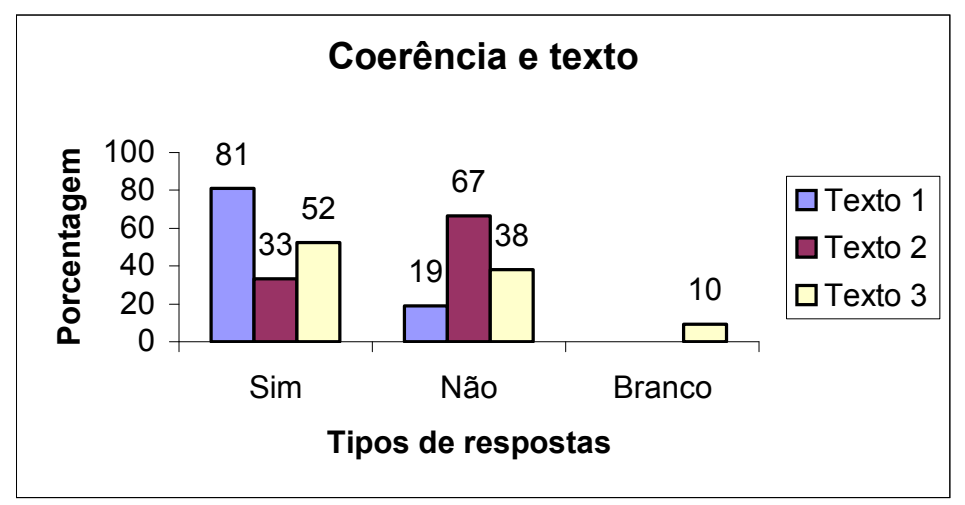

Gráfico 2: Interpretação da coerência textual para cada texto.

De acordo com as respostas, o texto 1 é o mais coerente $(81 \%)$, seguido pelo $3(52 \%)$ e pelo 2 (33\%). Assim, o texto 2 foi considerado o menos coerente e, anteriormente, como o mais errado. Ao pedirmos que os alunos identificassem os 


\begin{tabular}{|l|l|l|l|l|l|l|}
\hline InterteXto & Uberaba & UFTM & v. 1 & p. 35-55 & 2008 - jan. / jun. & ISSN 1981-0601 \\
\hline
\end{tabular}

referentes das $A C$, pretendíamos verificar se os referentes indicados por eles estavam correlacionados conceitualmente às $A C$ ou não. Como foi exposto na metodologia, cada resposta foi contabilizada conforme se mostra na TAB 4.

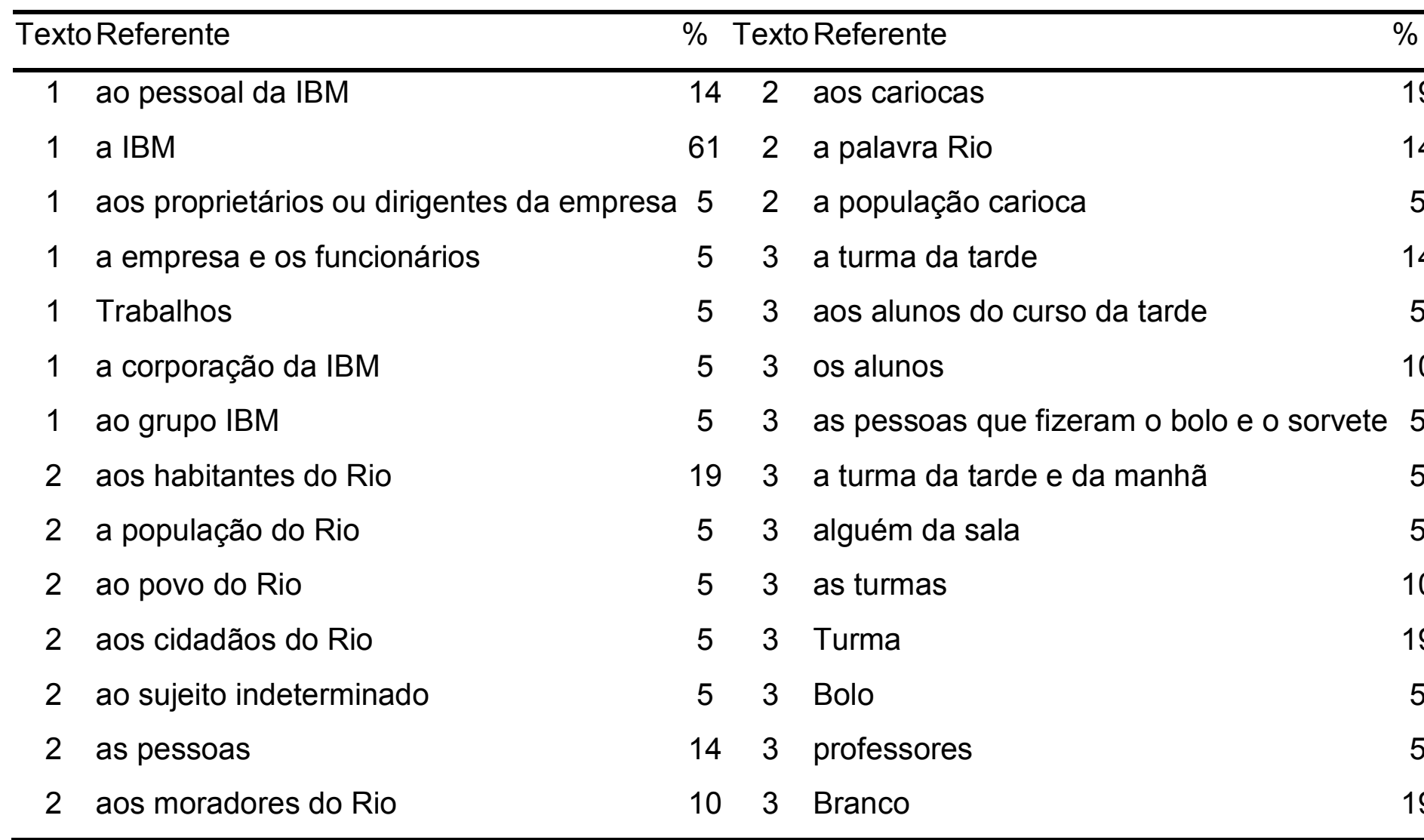

TABELA 4: Tipo de referente apresentado pelos alunos para cada texto usado no experimento.

Os resultados obtidos com os experimentos apresentados na metodologia podem ser resumidos assim:

1. Os universitários compreenderam perfeitamente a $A C$, pois poucos alunos identificaram a não-concordância entre a anáfora e 
o antecedente como um erro. Assim, podemos dizer que eles consideraram os textos coerentes e identificaram os referentes dessas anáforas.

2. No entanto, ao serem questionados sobre 0 referente das anáforas, ora simplesmente repetiram o antecedente tal como apresentado no texto [-PI], ora optaram por estabelecer uma concordância com a anáfora [+PI], e apenas uma minoria não conseguiu identificar o referente anafórico.

3. Os textos influenciaram as respostas dos universitários, na ora de indicar erros, de optar pela coerência ou não e de indicar os referentes das AC.

\section{Discussão}

A finalidade do experimento era verificar se os sujeitos compreenderiam a $A C$ e se identificariam o referente dessa anáfora. Os resultados indicaram que isso ocorreu, pois os universitários a consideraram coerente. $O$ fato de a $A C$ não concordar em número com o seu antecedente parece não ter influenciado o processo de compreensão, tanto é que, quando perguntamos aos alunos universitários se os textos apresentavam erros, apenas uma minoria considerou a não-concordância entre a anáfora e o antecedente um erro, de forma que para a maioria os textos eram coerentes.

Os textos do experimento aplicado em universitários, para serem interpretados, não dependiam de maiores conhecimentos lingüísticos dos leitores, mas apresentavam um fator que poderia complicar a sua compreensão: a presença da $\mathrm{AC}$, que estabelecia uma não-concordância de número com seu antecedente. Essa anáfora se associa, conceitualmente, a um antecedente 
textual, mas não se refere à mesma entidade evocada pelo antecedente. Para resolvê-la, o leitor deve estabelecer relações conceituais entre ela e o seu antecedente. Acreditamos que, ao ler o antecedente, o leitor evoca um frame ${ }^{4}$ e, diante da $\mathrm{AC}$, ativa conceitos contidos no frame do item antecedente e seleciona um desses conceitos, estabelecendo, então, a associação entre o pronome e o conceito selecionado. Os frames são ativados a partir do conteúdo explícito de palavras, combinações de conteúdos de palavras e segmentos textuais interpretados (GRAESSER e KREUZ, 1993).

Observemos o texto 1 do primeiro experimento realizado com alunos universitários:

1. Depois do colégio, minha irmã foi trabalhar na IBM. Eles fizeram uma boa proposta para ela.

De acordo com seus conhecimentos gerais, o leitor sabe que IBM é uma indústria que fabrica computadores. Sabe que uma indústria tem funcionários, gerentes, diretores, etc. Assim, ao ler eles, deve selecionar um desses conhecimentos para estabelecer a associação referencial. Ainda usando os conhecimentos, o leitor associa eles a funcionários, gerentes ou diretores, uma vez que o contexto explicita que houve uma proposta e, normalmente, admitimos que quem propõe são pessoas [+HUMANO], associadas a conceitos como os de AGENTES da proposta.

Por exemplo, para esse texto, ao serem questionados sobre qual seria o referente da $A C$, os alunos universitários indicaram o próprio antecedente ou sinônimos e atributos de um frame possível para IBM, como O PESSOAL DA IBM,

\footnotetext{
${ }^{4}$ Um frame é uma estrutura conceitual que contém informações textuais e de nossos conhecimentos, as quais são integradas para a construção do sentido do texto. Assim, essas estruturas contêm informações sobre pessoas, objetos, ações, eventos e conceitos abstratos que são ativados durante a leitura e integrados às informações explicitadas no texto, ou proposições. Em suma, um princípio de organização que abrange tanto a representação do conhecimento como a semântica (NERLICH et al., 2000).
} 
OS FUNCIONÁRIOS, OS PROPRIETÁRIOS OU DIRIGENTES DA EMPRESA. Isso indica que os alunos compreenderam a AC. Podemos então afirmar que eles foram capazes de ativar um conjunto de conhecimentos necessários para compreender o texto.

Acreditamos que todos compreenderam a $A C$, mas tiveram estratégias diferentes para indicar o seu referente. Eles optaram pelo próprio antecedente ou indicaram atributos ativados para o frame de IBM. Indicaram 0 antecedente considerando um conhecimento gramatical segundo o qual a anáfora deve retomar o seu antecedente, ou, simplesmente, ignoraram tal violação e apontaram os conceitos ativados pelo antecedente. Ou seja, em ambos os casos, eles ativaram o frame para IBM, mas alguns se guiaram pela violação morfológica, e outros não.

Nesse experimento, constatamos que os alunos compreenderam a AC, pois não detectaram a não-concordância de número entre antecedente e anáfora como um erro e consideraram os textos coerentes. Ao serem questionados sobre o item ao qual a anáfora se referia, eles indicaram os antecedentes, mas muitos alunos demonstraram ter ativado outros conceitos possíveis para os frames desses antecedentes. Isso demonstrou que eles compreenderam as anáforas, mas que ficaram divididos entre os antecedentes e os conceitos ativados por esses antecedentes. Assim, casos como os da AC são compreendidos, mas os alunos ora fazem uma generalização, citando o próprio conceito que origina o frame, ora uma seleção ao indicarem conceitos relacionados a esse frame. Também podemos considerar a influência dos conhecimentos lingüísticos na indicação do referente anafórico, pois os alunos sabem que as anáforas retomam seus antecedentes, e ao indicarem o referente, podem ter optado pelo antecedente devido a esse conhecimento. 
Constamos, através dos experimentos, que apenas uma minoria citou a não-concordância nominal como um erro do texto. Isso parece indicar que, na verdade, os sujeitos perceberam o sentido do texto, compreenderam que a AC remete a um antecedente não correferencial, pois consideraram os textos como coerentes e reconheceram o referente dessa anáfora.

Mas, se isso realmente aconteceu, por que indicaram que os textos apresentavam erros? Acreditamos que, ao serem questionados sobre a possibilidade de erros, eles inferiram que os textos deveriam ter erros, caso contrário, não seriam questionados. Isso está relacionado ao cotidiano escolar, quando costumam responder a perguntas, colaborando com o professor. Assim, se este faz uma determinada pergunta num contexto escolar, ele espera uma resposta direcionada à pergunta feita. Ou seja, os alunos indicaram erros, porque ao serem questionados sobre a presença desses, eles devem ter inferido que os textos apresentavam erros, caso contrário, não estaríamos perguntando a esse respeito.

Swinney e Osterhout (1990) estudam a geração de inferências durante a leitura e apresentam evidências para a distinção de duas classes de inferências: as automáticas (perceptivas), que são resolvidas a partir do próprio texto, mas que podem necessitar de alguns conhecimentos extralingüísticos, e as pragmáticas ${ }^{5}$ são geradas apenas com base em nossos conhecimentos de mundo. Os autores afirmam que a literatura pertinente apresenta uma enorme variedade de tipos de inferência, mas que essa variedade está relacionada, na verdade, em função das condições em que as inferências são examinadas. Ou seja, nos estudos sobre as inferências, devemos considerar a influência de três importantes aspectos: as crenças, ou melhor, as expectativas que o ouvinte ou leitor cria em torno das

\footnotetext{
${ }^{5}$ Outros pesquisadores preferem chamar as primeiras de inferências de bridging ou conectivas (CLARK, 1977, SINGER, 1994) e elaborativas (SINGER, 1994).
} 
tarefas a serem executadas durante o experimento, o modo de apresentação dessas tarefas e o modo de responder a essas tarefas. Analisando os nossos experimentos com os alunos universitários, pensamos que dois importantes aspectos devem ser levados em consideração sobre compreensão textual: o tipo de tarefa a ser executada e as expectativas que o leitor gera a partir dessa tarefa.

No experimento, não realizamos medições on-line. $O$ fato é que ao questionarmos os alunos sobre a possibilidade de erros, talvez eles tenham inferido que, na verdade, queríamos saber sobre a gramaticalidade dos textos. Desse modo, poderiam ter criado expectativas em relação ao tipo de tarefa realizada no experimento, e isso pode ter influenciado a resposta dos alunos e, conseqüentemente, a compreensão anafórica.

Van Den Broek, Fletcher e Risden (1993) também afirmam que fatores como os sujeitos (com diferentes conhecimentos e motivações, por exemplo), as instruções dadas aos sujeitos, o tipo de tarefa realizada (pergunta e resposta ou recall, por exemplo) e o material utilizado (texto, gênero, dificuldade) podem influenciar a geração de inferências nas pesquisas. Além de considerarmos que as perguntas podem ter influenciado as respostas, devemos ressaltar que o experimento foi aplicado numa sala de aula, durante a aula de Português e com a presença do professor da disciplina. Ou seja, isso também pode ter influenciado as suas expectativas ao responderem às perguntas, pois eles podem ter achado que o objetivo do experimento era a verificação de seus conhecimentos gramaticais, pelo fato de o experimento ter sido realizado na aula de Português (SINGER, 1994). Singer et al. (1992) afirmam que, sob certas condições de experimento, predominantemente, as pessoas julgam a plausibilidade dos fatos questionados, verificando se insinuam ou declaram algo. Isso reforça nossa hipótese de que os alunos podem ter sido influenciados pelas perguntas e, por isso, podem ter indicado problemas nos textos, apesar de tê-los compreendido. 
Também relacionada a essa questão das respostas dos alunos a perguntas realizadas após a leitura dos textos está a geração de inferências. Uma questão pertinente ao estudo das inferências é saber se elas são feitas durante a compreensão ou depois, denominadas por Swinney e Osterhout (1990), respectivamente, perceptivas e cognitivas. Alguns experimentos já demonstraram que algumas são feitas on-line, durante a leitura, e outras não. Para detectarmos as realizadas durante o processo, por exemplo, há experimentos que medem o tempo de leitura, a duração da fixação de olhos, decisão lexical, etc. (LONG; GOLDING; GRAESSER; CLARK, 1990; SEIFERT, 1990). Mas há inferências geradas após a compreensão e são detectadas, por exemplo, através de perguntas. Graesser e Clark (1985) desenvolveram e aplicaram a metodologia de pergunta e resposta para manipular as inferências baseadas no conhecimento dos leitores. Essa discussão do melhor tipo de metodologia para a verificação de inferências é muito complexa e extensa ${ }^{6}$. Mas é importante ressaltar que embora os experimentos não garantam se uma inferência ocorre de maneira automática ou posteriormente à leitura, mesmo assim os resultados podem dar pistas sobre o processamento. Alguns pesquisadores acreditam que a resolução da anáfora associativa $^{7}$ é feita durante a leitura (CLARK, 1977; LONG et al, 1990; SINGER et al., 1992; SINGER, 1994). Se isso realmente acontece, mesmo com as anáforas conceituais $^{8}$, podemos concluir que as perguntas, realmente, influenciaram a leitura e compreensão da $\mathrm{AC}$, pois os alunos leram os textos, construíram certas expectativas que puderam ser modificadas após a leitura das perguntas.

\footnotetext{
${ }^{6}$ Numa parte deste trabalho, por exemplo, trabalhamos com experimentos de perguntaresposta e, em outra, com experimentos de tempo. $\mathrm{Na}$ verdade, não podemos caracterizar um experimento melhor do que outro, mas, realizando os dois, poderemos ter mais pistas sobre o processamento e compreensão da AC.

${ }^{7}$ Chamadas por CLARK (1977) de bridging inferences.

${ }^{8}$ Ressaltamos que CLARK (1977) estudou apenas sintagmas nominais.
} 
A análise dos resultados indica, também, que os textos influenciaram nas respostas dos alunos. Os resultados demonstraram que o processamento dos três textos foi diferenciado. $O$ fato de os alunos interpretarem esses textos diferentemente indica que a organização do texto e o modo de apresentação podem influenciar na compreensão de textos e na interpretação anafórica. É interessante observar que os alunos aceitaram mais o texto elaborado para o experimento (1), seguido por um texto produzido por uma professora numa reunião de classe (3), sendo que o menos aceito foi uma transcrição de uma fala (2). O texto 2, de acordo com os alunos, foi o que mais apresentou erros, seguido pelos textos 3 e 1 . Os resultados também indicaram ter havido influência dos textos no julgamento sobre a coerência textual. Outra influência textual foi verificada na indicação de outros referentes para a AC. O texto 3 foi o que mais possibilitou essas indicações. Isso pode ter ocorrido porque ele apresentava mais itens lexicais, obrigando o leitor a ativar um número maior de frames e, portanto, dificultando a compreensão anafórica.

Tal fato demonstrou que os textos influenciaram as respostas dos alunos e que foram processados diferentemente. Relacionados a essa influência do texto nas respostas dos alunos estão dois fatores: a modalidade de apresentação e a própria organização textual.

Verificamos que os textos da fala foram menos aceitos do que o texto da escrita. Os alunos estabeleceram relações entre a AC e o antecedente, construíram os frames para esses textos, mas a organização textual influenciou na compreensão anafórica. $O$ texto da escrita foi mais aceito do que os da fala. Por hipótese, podemos considerar que os alunos parecem ser sensíveis ao nível de registro ou de variação. 


\begin{tabular}{|l|l|l|l|l|l|l|}
\hline InterteXto & Uberaba & UFTM & v. 1 & p. 35-55 & 2008 - jan. / jun. & ISSN 1981-0601 \\
\hline
\end{tabular}

Assim, tudo indica que os alunos compreenderam os textos e as $A C$, mas foram influenciados por seus conhecimentos sobre as modalidades e, por isso, consideraram os textos como mais errados e mais incoerentes.

\section{Considerações finais}

Com base nos resultados, concluímos que os universitários compreendem a AC, mas não a julgam natural e usam estratégias diferentes para processá-la. Cabe lembrar que a Teria dos Frames pode ajudar a explicar como o leitor compreende o texto, pois ela é uma teoria que aborda diferentes fatores que influenciam esse processo. Essa teoria permite uma análise lingüística do texto e também de aspectos cognitivos que possibilitam a compreensão e que, de certa forma, também são influenciados por aspectos sociais. Assim, percebemos que a leitura é influenciada por aspectos lingüísticos e extralingüísticos.

A partir dos resultados, constatamos que os sujeitos compreenderam as anáforas conceituais, foram capazes de ativar frames semânticos para interpretálas, mas não as consideraram como naturais e corretas. Isso ocorreu porque eles estavam presos aos conhecimentos lingüísticos ou devido ao direcionamento da pergunta, mas o experimento realizado não elucidou tal mistério.

O próximo passo será realizar um experimento de leitura on-line para verificar a leitura da AC. Verificamos que os textos e as perguntas influenciaram o reconhecimento anafórico, decidimos trabalhar com textos formados apenas por duas sentenças, com distância semelhante entre a anáfora e o antecedente, no segundo experimento. Apesar de concluirmos que os sujeitos compreenderam as $A C$, acreditávamos que a AC deveria ter um maior custo cognitivo do que a AP e por isso aplicamos o experimento de tempo de leitura das anáforas. 


\begin{tabular}{|l|l|l|l|l|l|l|}
\hline InterteXto & Uberaba & UFTM & v. 1 & p. 35-55 & 2008 - jan. / jun. & ISSN 1981-0601 \\
\hline
\end{tabular}

\section{Referências Bibliográficas}

BARSALOU, Lawrence W.. Frames, concepts, and conceptual fields. In: LEHRER, Adrienne; KITTAY, Eva Feder. Frames, fields, and contrasts. New essays in semantic and lexical organization. New Jersey: Lawrence Erlbaum Associates, 1992.

CLARK, Herbert. Brinding. In: WASON, P.; JOHNSON-LAIRD, P. (Ed.). Thinking: readings in cognitive sciences. Cambridge: Cambridge University Press., 1977. GARNHAM, Alan; OAKHILL, Jane. Discourse processing and text representation from a 'Mental models' Perspective. Language and cognitive processes, Hove: Lawrence erlbaum Associates, 7, 1992.

GERNSBACHER, Morton Ann. Comprehending conceptual anaphors. Language and cognitive processes, Hove: Lawrence Erlbaum Associates, v. 6 (2), 1991. GRAESSER, A. C.; CLARK, L. F. Structures and Procedures of Implicit Knowledge. New Jersey, Ablex, 1985.

GRAESSER, A. C.; KREUZ, R. J.. A theory of inference generation during text comprehension. Discourse Processes, 16, 1993.

LONG, Debra L.; GOLDING, J. M.; GRAESSER, A. C.; CLARK, Leslie F. Goal, event, and state inferences: an investigation of inference generation during story comprehension. In: GRAESSER, Arthur C., BOWER, Gordon H. (ed.). Inferences and text comprehension.San Diego, Academic Press, 1990.

MARCUSCHI, L. Antônio. Anáfora indireta: o barco textual e suas âncoras. VII Jornada do CELSUL. Curitiba: Universidade Federal do Paraná, 16 e 17 de novembro, 2000. 
OAKHILL, Jane; GARNHAM, Alan; GERNSBACHER, Morton Ann; CAIN, Kate. How natural are conceptual anaphors?, Language and Cognitive Processes, Hove: Lawrence Erlbaum Associates, v.7 (3/4), 1992.

SEIFERT, Colleen M.. Content-based inferences in text. In: In: GRAESSER, Arthur C.; BOWER, Gordon H. (ed.). Inferences and text comprehension. New York: Academic Press, 1990.

SINGER, M.. Discourse inference processes. In: GERNSBAHER, M. A. (Ed.). Handbook of Psycholinguistics.New York: Academic Press, Chapter 14, 1994. SINGER, Murray; ANDRUSIAK, Peter; REISDORF, Paul; BLACK, Nancy L. Individual differences in bridging inference processes. Memory \& Cognition, Austin, v. 20 (5), 1992.

SWINNEY, David A.; OSTERHOUT. Infernce Generation during auditory language comprehension. In: GRAESSER, Arthur C.; BOWER, Gordon H. (ed.). Inferences and text comprehension. New York: Academic Press, 1990.

TYLER, L. K. ; MARSLEN-WILSON, W. The resolution of discourse anaphors: some on-line studies. Text, New York, v. 2, 1982.

VAN DEN BROEK, Paul. Comprehension and memory of narrative texts: inference and coherence. In: GERNSBAHER, M. A. (Ed.). Handbook of Psycholinguistics. New York: Academic Press, Chapter 16, 1994.

, FLETCHER, C. R.; RISDEN, K. Investigations of inferencial processes in reading: a theoretical and methodological integration. Discourse Processes, 16, 1993. 